\title{
Augmented-reality integrated robotics in neurosurgery: are we there yet?
}

\author{
Karthik Madhavan, MD, John Paul G. Kolcun, BS, Lee Onn Chieng, BS, and Michael Y. Wang, MD \\ Department of Neurological Surgery, University of Miami Miller School of Medicine, Miami, Florida
}

Surgical robots have captured the interest-if not the widespread acceptance-of spinal neurosurgeons. But successful innovation, scientific or commercial, requires the majority to adopt a new practice. "Faster, better, cheaper" products should in theory conquer the market, but often fail. The psychology of change is complex, and the "follow the leader" mentality, common in the field today, lends little trust to the process of disseminating new technology. Beyond product quality, timing has proven to be a key factor in the inception, design, and execution of new technologies. Although the first robotic surgery was performed in 1985, scant progress was seen until the era of minimally invasive surgery. This movement increased neurosurgeons' dependence on navigation and fluoroscopy, intensifying the drive for enhanced precision. Outside the field of medicine, various technology companies have made great progress in popularizing co-robots ("cobots"), augmented reality, and processor chips. This has helped to ease practicing surgeons into familiarity with and acceptance of these technologies. The adoption among neurosurgeons in training is a "follow the leader" phenomenon, wherein new surgeons tend to adopt the technology used during residency. In neurosurgery today, robots are limited to computers functioning between the surgeon and patient. Their functions are confined to establishing a trajectory for navigation, with task execution solely in the surgeon's hands. In this review, the authors discuss significant untapped technologies waiting to be used for more meaningful applications. They explore the history and current manifestations of various modern technologies, and project what innovations may lie ahead.

https://thejns.org/doi/abs/10.3171/2017.2.FOCUS177

KEY WORDS robotics; augmented reality; virtual reality; Google Glass; Project Tango; spine; navigation

$\mathrm{T}$ HE steady pace of progress must be surpassed to make history. Today, technological advancement has reached a feverish speed: innovation, integration, and optimization have become touchstones of surgical excellence. We find no better example than the incorporation of robotics and augmented reality into modern neurosurgery. These systems enhance the surgeon's ability to perceive and act, extending surgical capacity beyond the limitations of physical perception.

Robotic systems have long been the dream of inventors, futurists, and science fiction authors alike. Current systems are more accurately termed co-robots, or "cobots," because they interact with human operators, rather than functioning independently. A variety of cobot systems are used today to improve planning, navigation, and surgical dexterity. Virtual reality (VR) refers to artificially generated environments for user perception and interaction. In contrast, augmented reality (AR) is a projection of computer-generated virtual components onto the user's real surroundings. Both have been used for surgical training in a variety of disciplines, as either a supplement to or a replacement of traditional cadaver or animal models. Modern advances in haptics - the simulation of tactile sensations - have contributed to the quality of virtual and augmented experiences.

In this review, we will briefly describe the history and 
current trends of robotic systems and VR/AR platforms in neurosurgery. Furthermore, we propose a new synthesis of these independent devices for investigation and eventual product development.

\section{Methods}

We performed a detailed search of the Google Scholar search engine and PubMed database for the terms "robotics," "neurosurgery," "spine," "brain," "augmented reality," and "virtual reality," both separately and in combination. Our search strategy and criteria for the inclusion or exclusion of studies were in compliance with the Preferred Reporting Items for Systemic Reviews and Meta-Analyses (PRISMA) guidelines (Fig. 1).

\section{Current Technologies \\ Robotic Systems}

Robots have intrigued scientists and the general public alike since the dawn of modern science. The term "robot" was coined in 1921 from the Czech word "robota," meaning "forced labor." ${ }^{48}$ It probably referred to tasks performed by very simple automated devices. Sixty-four years later, the first robot-assisted surgery was performed in 1985 by Shao et al., using the PUMA 200 robot. $^{50}$ These advances aided the development of laparoscopic surgery in 1987. ${ }^{21}$ There was limited acceptance of robotics in neurosurgery until the advent of minimally invasive surgery (MIS), which is highly dependent on fluoroscopy (spine) and navigation (cranial). ${ }^{26}$ Because navigation or fluoroscopy could establish a safe approach to areas of interest, systems were developed with limited automation, such as the da Vinci or Renaissance robots (described below). ${ }^{5,19,28-31,39,60}$ Early robotic models were constrained to deployment at one location. To reach other areas, the machine had to be moved around the patient. This limitation was overcome by introducing additional robotic arms to the system. Next, more instruments and cameras were made available for the robotic arms. The discovery and exploitation of tumor markers provided additional visual clarity by localizing and distinguishing the tumor in the surgical field. ${ }^{42,45}$

Modern materials and miniaturization have allowed the development of new systems uniquely designed for the surgical theater. Perhaps most famously, the da Vinci surgical system (Intuitive Surgical) has been successfully used in several surgical specialties, predominately in the chest and abdominal cavity. Although the da Vinci robot has not found wide application in neurosurgery, it has been investigated for use in interbody fusion and skull base surgery.5,17

Robotic systems such as Spine Assist and Renaissance (Mazor Robotics) have been developed to guide screw placement in spinal neurosurgery. ${ }^{11,12}$ Although they are called robotic systems, these are truly cobot systems, which assist the human execution of tasks (e.g., screw placement). These systems rely on screw trajectories planned by the surgeon, based on preoperative CT imaging. In the operating room (OR), the robot is mounted on a frame attached to a bony element, such as the spinous

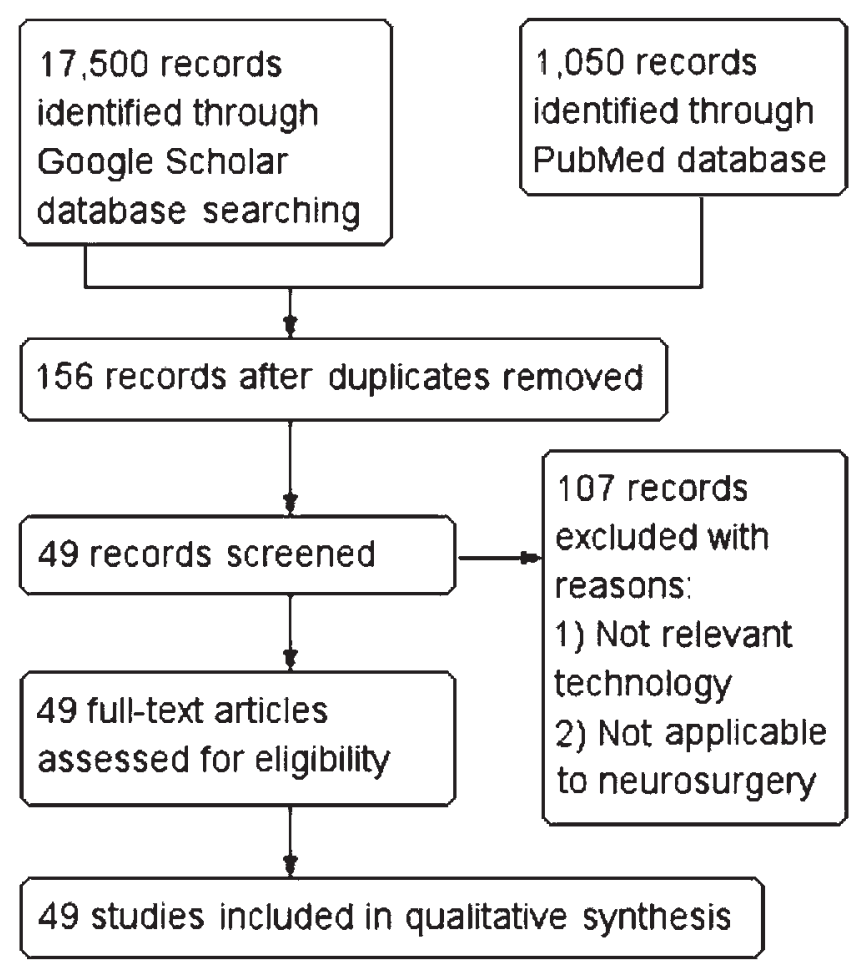

FIG. 1. Flow chart showing the PRISMA search strategy for study inclusion and exclusion.

process or iliac crest. Fluoroscopy is performed with fiducial markers, and synchronized with preoperative images containing the planned trajectory. The robotic device then aligns itself with that trajectory, providing physical guidance for accurate drill work and instrumentation. ${ }^{25,54}$

Recently, another system with similar abilities was approved for use in Europe: the ROSA robot (Medtech). This robot uses an intraoperative O-arm (Medtronic Inc) to scan the patient and integrate information to its system with markers in place. ${ }^{9}$ Both of these devices are parallel manipulators with a few degrees of freedom. They function in a semiactive mode, aligning instruments for pedicle screw placement. This is connected to the central processing unit (CPU), which is essentially a computer that integrates the preoperative CT scan to the intraoperative radiographic image. ${ }^{32}$ The accuracy of pedicle screw placement has been quite phenomenal. Currently, there are only a handful of clinical trials of robotic technology in neurosurgery, with a major emphasis in spine surgery. We analyzed 3 studies with a total of 166 patients who were randomized to receive robotic pedicle screw placement or were treated via an open approach. We found that there was higher accuracy in screw placement in the robotic group, although it did not reach statistical significance ( $\mathrm{p}$ $=0.92)\left(\right.$ Table 1 and Fig. 2). ${ }^{20,24}$

Cranial applications for these robots include stereotactic deep brain stimulator placement, laser thermal ablation therapy, tumors, and endoscope navigations. ${ }^{6,8,18,56} \mathrm{In}$ cranial surgeries, the preoperative MRI is merged with the intraoperative CT or MRI scan. The availability of intraoperative imaging can limit the use of the robot.

NeuroArm (University of Calgary) is a tele-operated 
TABLE 1. Three studies with a total of 166 patients who were randomized to receive robotic pedicle screw placement or screw placement via an open approach

\begin{tabular}{|c|c|c|c|c|c|c|c|c|}
\hline $\begin{array}{l}\text { Authors } \\
\text { \& Year }\end{array}$ & $\begin{array}{l}\text { Study } \\
\text { Design }\end{array}$ & Country & $\begin{array}{l}\text { No. of } \\
\text { Pedicle } \\
\text { Screws }\end{array}$ & $\begin{array}{l}\text { Placement } \\
\text { Method, } \\
\text { No. of Pts }\end{array}$ & Vertebral Level & $\begin{array}{l}\text { Surgical } \\
\text { Indication }\end{array}$ & Key Outcome Measure(s) & $\begin{array}{l}\text { Mean FU in } \\
\text { Mos (range) }\end{array}$ \\
\hline $\begin{array}{l}\text { Hyun et } \\
\text { al., } \\
2016\end{array}$ & RCT & Korea & 270 & $\begin{array}{l}\text { Robot: } 30 \\
\text { FH: } 30\end{array}$ & NA & $\begin{array}{l}\text { Degenerative } \\
\text { disease }\end{array}$ & $\begin{array}{l}\text { Screw accuracy, facet joint violation, } \\
\text { radiation exposure, VAS, ODI, learn- } \\
\text { ing curve, hospital stay, revision rate }\end{array}$ & $16.3(9-22)$ \\
\hline $\begin{array}{l}\text { Roser } \\
\text { et al., } \\
2013\end{array}$ & $\mathrm{RCT}$ & Germany & 148 & $\begin{array}{l}\text { Robot: } 18 \\
\mathrm{FH}: 10\end{array}$ & Thoracolumbosacral & $\begin{array}{l}\text { Degenerative } \\
\text { disease }\end{array}$ & $\begin{array}{l}\text { Screw accuracy, radiation exposure, } \\
\text { surgical time }\end{array}$ & $\begin{array}{c}\text { None; just as- } \\
\text { sessment } \\
\text { of accuracy }\end{array}$ \\
\hline
\end{tabular}

$\mathrm{FH}$ = freehand; FU = follow-up; NA = not available; ODI = Oswestry Disability Index; $\mathrm{PR}=$ per robot; pts = patients; $\mathrm{RCT}$ = randomized controlled trial; $\mathrm{VAS}=$ visual analog scale.

We demonstrated that there was higher accuracy in screw placement in the robotic group, although it did not reach statistical significance $(p=0.92)$.

robotic system designed specifically to withstand strong magnetic fields. ${ }^{34,55}$ This allows high-quality intraoperative MRI without halting the procedure. The surgical workstation uses a 3D visual display with auditory and haptic feedback for full immersion. Finally, the system includes a number of mechanical components to improve surgical dexterity, including tremor filters, motion scaling, and directional locks.

The haptic feedback in these systems was based on the surface consistency and mechanical characteristics of the control interface. Several grueling testing sessions were required to determine those properties. Newer software products and languages, such as Swift (Apple Inc.), have enabled virtual assessment of haptic systems. However, several years of development may be necessary before these advances reach medical devices.

\section{Control Systems}

Perhaps as important as the robot itself, its means of control-whether direct or remote-can significantly impact the quality of user-device interaction and subsequent surgical outcomes. Some systems (such as the above-described Renaissance) require no intraoperative controls, because they merely execute functions programmed before surgery and do not directly interact with the patient. Truly operative systems, such as the da Vinci or NeuroArm, do require elaborate but intuitive consoles for user control. These control panels, however, require new skills-with new learning curves-for surgeons to master. Regardless of a practitioner's age or conventional surgical training, good training and continued practice are required to perform safe and effective surgery with these systems. ${ }^{35,59}$

A control system that instead translates commands from natural human hand motion to robotic mechanical output with high fidelity would seem desirable. Such technologies are in development, predominantly for patients who have undergone amputations. Current models of the RoboArm (Unlimited Tomorrow Inc.) feature articulation at finger, wrist, elbow, and shoulder joints with seeming precision (http://theroboarm.com). It is designed for control by a glove or other sensors, such that the RoboArm mirrors the motion of the user's own limb.

But paradoxically, the most advanced control systems may sacrifice authority to the robot itself. The field of artificial intelligence has seen dramatic success in recent years in the decision-making ${ }^{7}$ and learning capacity of machines as well as their ability to interact with human operators using natural language systems. ${ }^{37,44,51}$ Indeed, this year a team at the Children's National Medical Center

\begin{tabular}{|c|c|c|c|c|c|c|c|c|c|c|}
\hline \multirow[b]{2}{*}{ Study or Subgroup } & \multicolumn{2}{|c|}{ Experimental } & \multicolumn{2}{|c|}{ Control } & \multirow[b]{2}{*}{ Weight } & \multirow{2}{*}{$\begin{array}{c}\text { Odds Ratio } \\
\text { M-H, Fixed, } 95 \% \mathrm{Cl}\end{array}$} & \multirow{2}{*}{\multicolumn{4}{|c|}{$\begin{array}{c}\text { Odds Ratio } \\
\text { M-H, Fixed, } 95 \% \mathrm{Cl}\end{array}$}} \\
\hline & Events & Total & Events & Total & & & & & & \\
\hline Hyun 2016 & 0 & 130 & 2 & 138 & $14.8 \%$ & $0.21[0.01,4.40]$ & $\longleftarrow$ & $\Longrightarrow$ & & \\
\hline Kim $2016^{24}$ & 10 & 148 & 14 & 158 & $77.4 \%$ & $0.75[0.32,1.73]$ & & & & \\
\hline Roser 2013 & 1 & 72 & 1 & 40 & $7.8 \%$ & $0.55[0.03,9.03]$ & & & & \\
\hline Total $(95 \% \mathrm{Cl})$ & & 350 & & 336 & $100.0 \%$ & $0.65[0.30,1.41]$ & & & & \\
\hline Total events & 11 & & 17 & & & & & & & \\
\hline $\begin{array}{l}\text { Heterogeneity: } \mathrm{Chi}^{2}= \\
\text { Test for overall effec }\end{array}$ & $\begin{array}{l}0.65, \mathrm{df}= \\
Z=1.09\end{array}$ & $\begin{array}{l}(P=0 \\
=0.28\end{array}$ & $72) ; 1^{2}=$ & & & & 0.01 & Favors [experimental] & $\begin{array}{c}10 \\
\text { Favors [control] }\end{array}$ & 100 \\
\hline
\end{tabular}

FIG. 2. Three studies with a total of 166 patients who were randomized to receive robotic pedicle screw placement or treatment via an open approach. We found that there was higher accuracy in screw placement in the robotic group, although it did not reach statistical significance $(\mathrm{p}=0.92)$. M-H = Mantel-Haenszel. 
in Washington, DC, demonstrated a soft-tissue procedure (bowel anastomosis) in a porcine model with an autonomous robotic surgeon under human supervision alone. ${ }^{49}$ Although fully autonomous surgical robots are far from the market, in the near future we may expect voice-activated command capability for mechanical or imaging devices. As the quality of machine learning improves, surgical robots working with a particular user can learn that surgeon's preferences over time. In this context, deviation from programmed instructions is a major milestone for a robotic system. This development allows the machine to take on a functional aspect: the robot learns to achieve an outcome most effectively, rather than blindly performing a sequence of programmed tasks.

\section{The VR and AR Systems}

Although VR started with stereoscopic visualization of panoramic pictures in $360^{\circ}$ angles back in 1838 , the first simulator was not invented until 1929, in the form of a flight simulator. Much later (in 1960), head-mounted displays came into existence, and the term "virtual reality" was coined in 1987. Virtual reality for medical use was first documented by Viirre et al. in 1998 to cure spider phobia. ${ }^{15,58}$ Although VR and AR systems have been heavily marketed for entertainment, they have proved useful during surgical training by providing increasingly realistic simulations of simple and complex procedures. ${ }^{4}$ This allows residents to better practice surgical techniques before operating on a living patient. Furthermore, residents can gain valuable exposure to rare and difficult case scenarios while still in training.

Virtual reality simulation platforms have been associated with improvements in surgical trainees' operative time and overall performance in recent literature. ${ }^{36,41}$ Unfortunately, financial and legal barriers still impede a broader adoption of VR platforms for surgical training. ${ }^{22,63}$ In this study we examined VR and AR platforms that have proven effective in neurosurgical training, as well as newer technologies not yet adapted to surgical practice that may have a role beyond education, in the OR. Both robotics and AR and VR platforms have their own benefits and limitations with respect to each other (Table 2).

ImmersiveTouch (University of Illinois at Chicago) is an AR platform offering training modules for various techniques, including ventriculostomy, aneurysm clip- ping, and percutaneous spinal screw placement. ${ }^{1,33,62}$ In the original design, the user holds a haptic stylus beneath a high-resolution stereoscopic display. The haptic feedback combined with the linked motion between the user's hand and corresponding on-screen objects creates a highly realistic surgical simulation.

Another company, 3D Systems Inc. (formerly Simbionix), provides virtual endovascular training with haptic feedback for several modules, including acute stroke and aneurysm. ${ }^{10,23,40,47,52,53,57}$ These training sessions improve surgical proficiency and reduce patient exposure to fluoroscopy during procedures.

Recent advances in AR technology may have as yet unrecognized utility in the operating theater. Project Tango ${ }^{13,14}$ and Google Glass ${ }^{16,27,61}$ (Google Inc.) are 2 new AR products. Google Glass is a miniature computer, projector, and prism screen, combined in a pair of glasses. It can project any image - such as navigation or neuromonitoring-directly in front of the surgeon's eyes (in other words, to his glasses), eliminating the need to look away from the surgical site. ${ }^{61}$ Project Tango is software capable of 3D visuospatial scanning and reconstruction. This can be used to view the surgical area of interest and display useful AR imagery, such as tumor overlays, pedicle screw trajectories, or nearby vital anatomy.

The HoloLens (Microsoft Inc.) is another AR headset capable of projecting realistic virtual experiences onto the surrounding world. The visor can be calibrated for individual users, and displays high-quality 3D images in the visual field. The 3D speakers produce binaural audio, creating virtual sound sources at any point in the surrounding space. Importantly, neither the visor nor speakers disrupt the user's view or hearing of the actual surrounding world. ${ }^{16}$

Novel therapies in endovascular neurosurgery also hold potential for innovation through novel means of visualization. Coil embolization, for example, is known to carry significant risks to the patient. These risks could be mitigated by a more efficient system of introducing and tracking embolic materials. Recently, an external magnetic field was used to guide embolic magnetic microparticles into an aneurysm in a rabbit model. ${ }^{38}$ Although this technique remains under investigation, its applications may be limited in the age of MRI. Traceable embolic microparticles capable of navigation by other means could be visualized by AR projection. The surgeon could then verify the po-

TABLE 2. Robotics versus AR and VR-benefits, limitations, and future goals

\begin{tabular}{|c|c|c|c|}
\hline Device & Benefits & Drawbacks & Future Goals \\
\hline $\begin{array}{l}\text { Robotic } \\
\text { systems }\end{array}$ & $\begin{array}{l}\text { Mechanical precision during surgery } \\
\text { Minimally invasive surgical access } \\
\text { Execution of preprogrammed trajec- } \\
\text { tories }\end{array}$ & $\begin{array}{l}\text { Possibility of mechanical failure } \\
\text { Physical/spatial restrictions associated w/ } \\
\text { large, unwieldy robotic units } \\
\text { Imperfect sensory feedback to user console }\end{array}$ & $\begin{array}{l}\text { Increased functional capacity, w/ greater fail- } \\
\text { safes \& redundancies in case of malfunction } \\
\text { Greater miniaturization for efficient motions \& } \\
\text { improved maneuverability }\end{array}$ \\
\hline $\begin{array}{l}\text { VR \& AR } \\
\text { platforms }\end{array}$ & $\begin{array}{l}\text { Well-documented improvements in } \\
\text { surgical training } \\
\text { Intraop visualization of spatial param- } \\
\text { eters, display of imaging studies } \\
\text { Remote observation \& guidance by } \\
\text { surgical team }\end{array}$ & $\begin{array}{l}\text { Limited immersion of VR environments } \\
\text { Limited adoption for surgical training due to } \\
\text { cost of VR \& AR platforms } \\
\text { Few intraop applications of VR/AR technol- } \\
\text { ogy currently on market }\end{array}$ & $\begin{array}{l}\text { More immersive training scenarios, w/ a } \\
\text { broader range of sensory feedback, includ- } \\
\text { ing high-fidelity haptic systems } \\
\text { Development \& optimization of wearable } \\
\text { display systems for intraop use }\end{array}$ \\
\hline
\end{tabular}


sition and movement of the particles, while avoiding repeated fluoroscopy and the associated radiation exposure to the patient and surgical staff.

\section{Future Directions: a Virtual Vision}

The imagination has no limits: we can envision systems ranging from semiautomated devices with integrated scanners and surgical arms, to a fully operational humanoid machine. But these remain fantasies; let us consider a more concrete future for robotics in spinal neurosurgery. The ideal design will have elements of our current systems, but with far more independence. In the near future, we must incrementally develop and adopt the requisite technology.

The next generation of semiindependent machine will be a bed-mounted or attached system with 2 or more robotic arms. The arms will have 2-3 joints for articulation in 3 dimensions. They will be equipped with tools sufficient to place a percutaneous screw and rod system, operating from skin incision to rod insertion. The surgeon, positioned away from the table and sterile field, will be equipped with a headset and visor. The surgeon can view the operating field directly or from the viewpoint of the robotic arm, with an AR overlay. The AR display could include 3D visualizations of predetermined screw trajectories, and displays of pre- or intraoperative imaging. Furthermore, by synchronizing preoperative imaging studies with the AR platform, the visor could project target structures - a tumor, aneurysm, or specific spinal level-onto the patient for direct visualization, as well as projecting nearby vital anatomy for protection during the procedure. The surgeon can "command" specific spatial measure- ments to be projected onto the patient by the AR platform, obviating the need for physical measuring implements, marking pens, and the like, while improving operative precision (e.g., when measuring and cutting rods). The AR images could be then be manipulated with voice or gesture (including haptic feedback). Robotic arm positions can be optimized remotely, through voice commands or control systems mimicking the surgeon's arms. We envision control by sensor gloves or a similar system that lends itself to natural hand motions and haptic feedback with greater fidelity (Figs. 3 and 4).

\section{Limitations of the Study}

There is an easy pleasure in visualizing a science fiction level of robotic capability. However, the impediments to actual invention are as significant as they are numerous. ${ }^{2,43}$ The robots of today can reach a predetermined target if provided with a trajectory to follow, and if they are fixed in space to an immobilized frame. This is a far cry from the polydextrous machines we envision. In the following list we detail specific shortcomings in current technology, from the physical bedside demands of surgical robots to the more abstracted requirements of any medical device. These limitations must be overcome to achieve robotic systems with any measure of true independence.

1. Proprioception: it is necessary for the robot to realize the position of its arms at all times. This can be tracked with a camera, or proprioception must be built into the arms. Neither of these means are fully accurate with current technology.

2. Arm length: a short arm length is ideal for drilling cranial bone or sclerosed pedicle, but often fails to reach

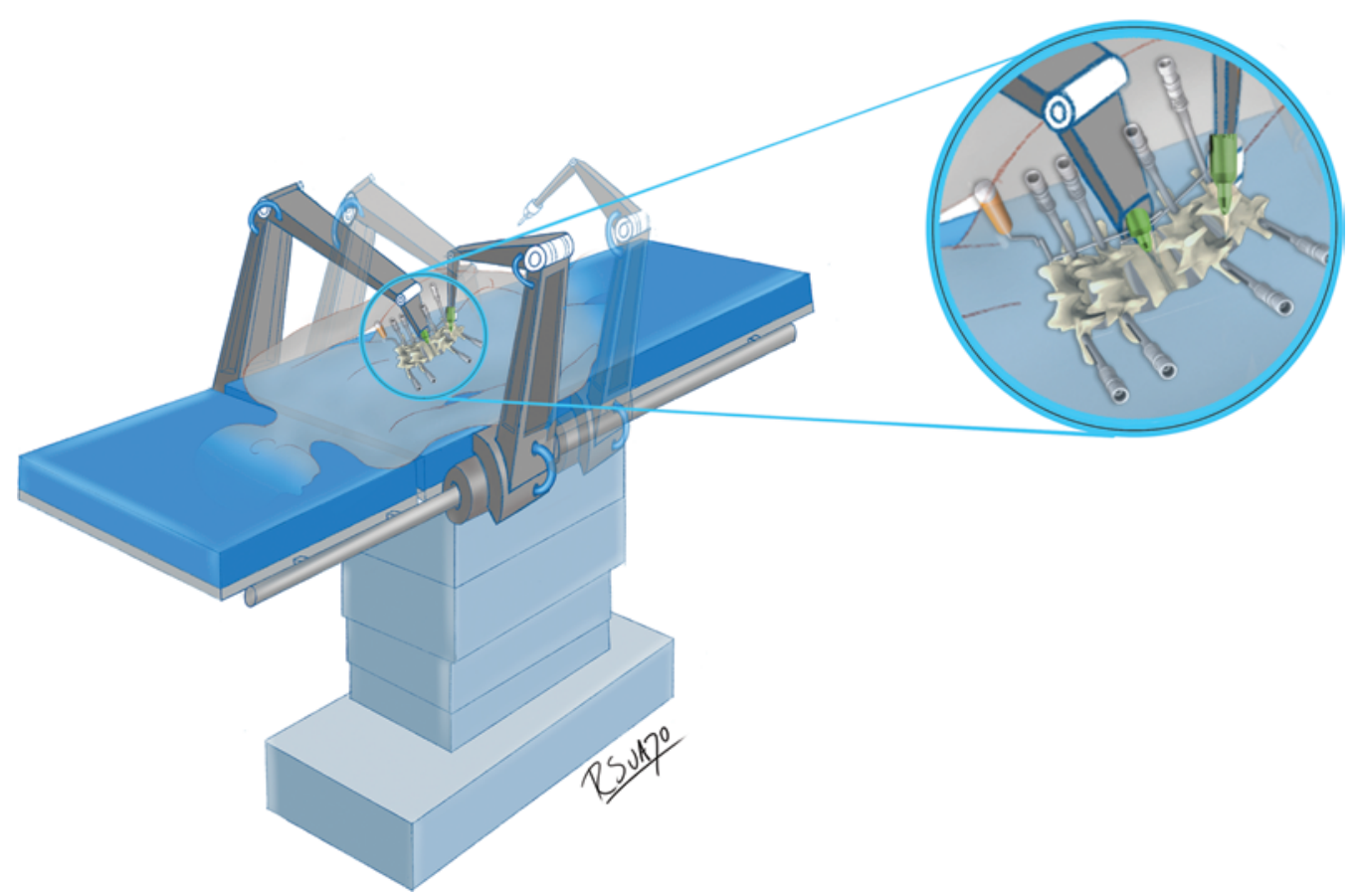

FIG. 3. Artist's depiction of a robotic system with multiple arms free to translate in 3 dimensions and along the length of the table. The inset shows the robotic arms equipped with drill heads and ready to make a pedicle screw trajectory. Copyright Karthik Madhavan. Published with permission. 

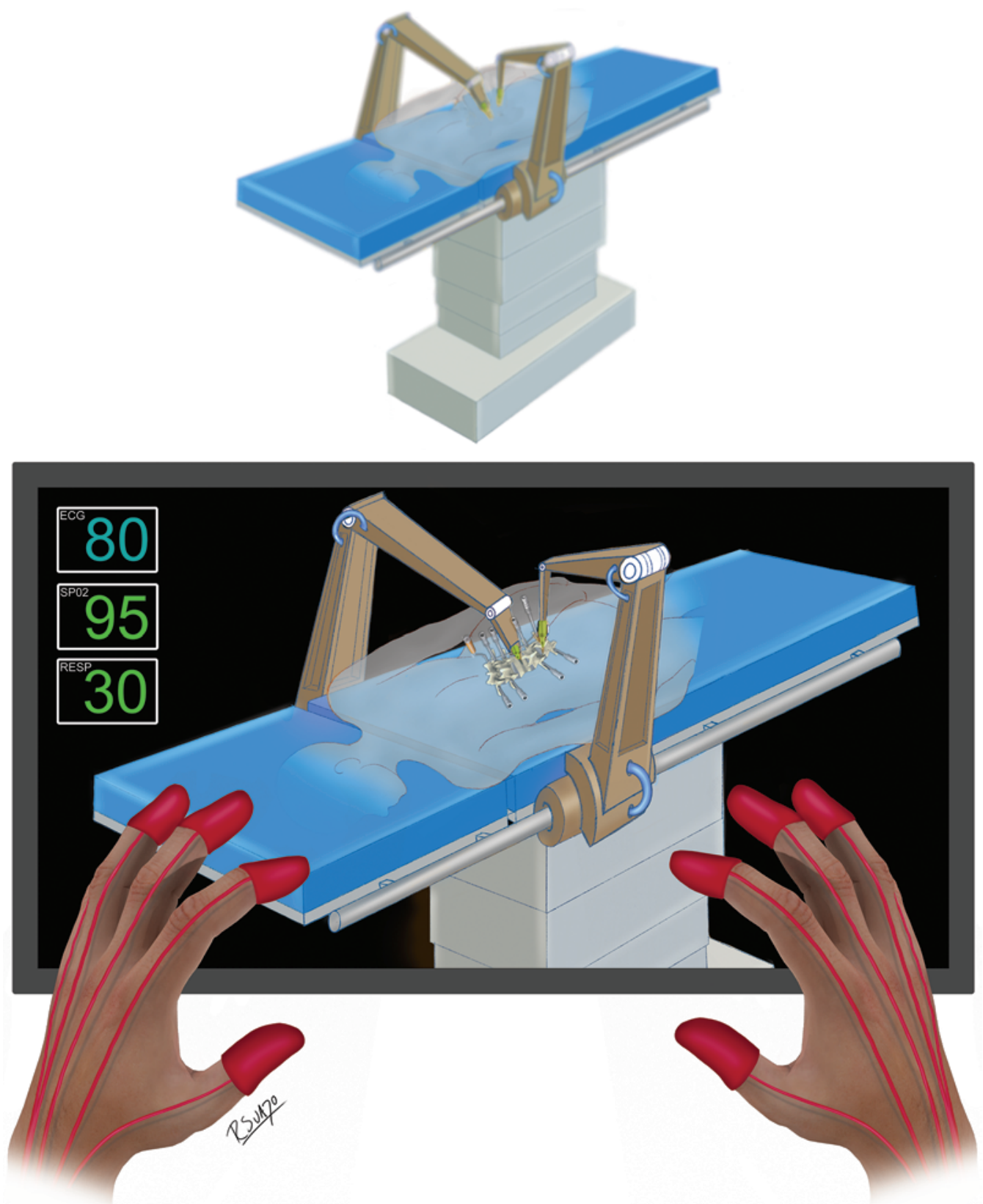

FIG. 4. Artist's depiction of a robotic system showing the surgeon positioned away from the sterile field, controlling the arms remotely based on AR projections of spine and pedicle screw trajectory over the patient, as seen in the monitor. Copyright Karthik Madhavan. Published with permission.

target depths. This, of course, varies with patient body habitus and the location of interest.

3. Integration: information from the camera or proprioception sensor must be integrated every millisecond to prevent an information lag while the arm is drilling into bone, or passing a needle into the brain.

4. Recalibration: due to natural tissue boundaries and variable consistency of tissue or tumor, mechanical resistance and displacement of the robotic arm will require constant repositioning. This must be performed by the surgeon, either remotely or directly. For example, even opening the cranial cavity will cause CSF egress, which can shift the cranial contents dramatically. Such alterations would render predetermined trajectories useless without proper adjustments.

5. User tracking: the position and orientation of the operator is paramount to ensure high-fidelity communication between surgeon and machine. For example, during AR projection overlay, it is essential to track the user's head position to construct an accurate $3 \mathrm{D}$ perspective from the angle of the viewer.

6. Multiple information processing systems: integrating multiple sensors or cameras for extensive real-time tracking can amplify individually insignificant errors from each 
device. The summation may render the device as a whole significantly inaccurate.

7. Precision: although we have primarily discussed other aspects of these robotic systems, the quality of mechanical function is obviously paramount. No degree of calculation or projection can correct a faulty motion. We have already seen lawsuits for inadvertent vascular injury leading to death of a patient. ${ }^{3}$

8. Smart implants: smart implants (e.g., a screw that "knows" its own position in space) are capable of tracking themselves and supply additional information for the computer to process. These devices, although in development, are not yet widely available on the market.

9. CPU: all of these systems require extremely powerful processing chips that are capable of understanding software and integrating information in milliseconds.

10. Fail-safes: there must be override systems in case of system malfunction or mechanical failure. These should include both software contingencies and mechanical redundancies.

11. Cost: these systems must minimize error, reduce OR and anesthesia time, and be cost-effective in the long term. The limited robotic systems available today are already quite expensive.

\section{Conclusions}

Today, although neurosurgery is still in its robotic infancy, we are able to perform technical maneuvers unimagined even 10 years ago. Even as CPU designs become increasingly sophisticated, the true innovations of our age will be in software. As we develop programs capable of rapid, high-fidelity control of machines with extreme, millimeter-scale precision, we will realize an unexplored potential for manipulation of the physical world.

Neurosurgery has traditionally been a field of pioneers, and we must carry that explorer's spirit into this century. Neurosurgeons often serve as the bridge between anatomy, engineering, and software. Extensive collaboration between biotechnology firms and surgeons is likely to drive our field further toward these projections. Our perspective allows only a small glimpse of the future of robotics in neurosurgery.

Our continued desire for MIS techniques must drive the development of new and better technologies. Ultimately, we as neurosurgeons should strive for techniques capable of treating pathological entities, while leaving our patients intact and without deficit. Just as the rise of MIS for neurosurgery spurred the adoption of robotic systems, the imminent technological advances we project must be embraced and adopted to expand our capacity for minimally invasive intervention.

\section{References}

1. Alaraj A, Luciano CJ, Bailey DP, Elsenousi A, Roitberg BZ, Bernardo A, et al: Virtual reality cerebral aneurysm clipping simulation with real-time haptic feedback. Neurosurgery 11 (Suppl 2):52-58, 2015

2. Alemzadeh H, Raman J, Leveson N, Kalbarczyk Z, Iyer RK: Adverse events in robotic surgery: a retrospective study of 14 years of FDA data. PLoS One 11:e0151470, 2016
3. Associated Press: Tampa hospital sued over robotic surgery that killed teacher. Florida Times-Union. December 17, 2003. (http://jacksonville.com/apnews/stories/121703/ D7VG8FM00.shtml) [Accessed March 15, 2017]

4. Badash I, Burtt K, Solorzano CA, Carey JN: Innovations in surgery simulation: a review of past, current and future techniques. Ann Transl Med 4:453, 2016

5. Beutler WJ, Peppelman WC Jr, DiMarco LA: The da Vinci robotic surgical assisted anterior lumbar interbody fusion: technical development and case report. Spine (Phila Pa 1976) 38:356-363, 2013

6. Brandmeir N, Acharya V, Sather M: Robot assisted stereotactic laser ablation for a radiosurgery resistant hypothalamic hamartoma. Cureus 8:e581, 2016

7. Cancer Discovery: Bringing precision medicine to community oncologists. Cancer Discov 7:6-7, 2017

8. Chan AY, Tran DK, Gill AS, Hsu FP, Vadera S: Stereotactic robot-assisted MRI-guided laser thermal ablation of radiation necrosis in the posterior cranial fossa: technical note. Neurosurg Focus 41(4):E5, 2016

9. Chenin L, Peltier J, Lefranc M: Minimally invasive transforaminal lumbar interbody fusion with the ROSA ${ }^{\mathrm{TM}}$ Spine robot and intraoperative flat-panel CT guidance. Acta Neurochir (Wien) 158:1125-1128, 2016

10. Davis GR, Illig KA, Yang G, Nguyen TH, Shames ML: An approach to EVAR simulation using patient specific modeling. Ann Vasc Surg 28:1769-1774, 2014

11. Devito DP, Kaplan L, Dietl R, Pfeiffer M, Horne D, Silberstein B, et al: Clinical acceptance and accuracy assessment of spinal implants guided with SpineAssist surgical robot: retrospective study. Spine (Phila Pa 1976) 35:2109-2115, 2010 [Erratum in Spine (Phila Pa 1976) 36:91, 2011]

12. Dreval ON, Rynkov IP, Kasparova KA, Bruskin A, Aleksandrovskii V, Zil'bernshtein V: [Results of using Spine Assist Mazor in surgical treatment of spine disorders.] Vopr Neirokhir 78:14-20, 2014 (Russian)

13. Drouin S, Kochanowska A, Kersten-Oertel M, Gerard IJ, Zelmann R, De Nigris D, et al: IBIS: an OR ready opensource platform for image-guided neurosurgery. Int J Comput Asssist Radiol Surg 12:363-378, 2017

14. Elmi-Terander A, Skulason H, Söderman M, Racadio J, Homan R, Babic D, et al: Surgical navigation technology based on augmented reality and integrated 3D intraoperative imaging: a spine cadaveric feasibility and accuracy study. Spine (Phila Pa 1976) 41:E1303-E1311, 2016

15. Garcia-Palacios A, Hoffman H, Carlin A, Furness TA III, Botella C: Virtual reality in the treatment of spider phobia: a controlled study. Behav Res Ther 40:983-993, 2002

16. Golab MR, Breedon PJ, Vloeberghs M: A wearable headset for monitoring electromyography responses within spinal surgery. Eur Spine J 25:3214-3219, 2016

17. Hong WC, Tsai JC, Chang SD, Sorger JM: Robotic skull base surgery via supraorbital keyhole approach: a cadaveric study. Neurosurgery 72 (Suppl 1):33-38, 2013

18. Hoshide R, Calayag M, Meltzer HS, Levy ML, Gonda DD: 352 Robot-assisted endoscopic third ventriculostomy. Neurosurgery 63 (Suppl 1):204, 2016 (Abstract)

19. Howard JJ, Abinahed J, Navkar N, Peyrat JM, Al-Ansari A, Sigalet DL, et al: Robotic-assisted minimally invasive surgery of the spine (RAMISS): a proof-of-concept study using carbon dioxide insufflation for multilevel posterior vertebral exposure via a sub-paraspinal muscle working space. Int J Med Robot [epub ahead of print], 2016

20. Hyun SJ, Kim KJ, Jahng TA, Kim HJ: Minimally invasive, robotic-vs. open fluoroscopic-guided spinal instrumented fusions - a randomized, controlled trial. Spine (Phila Pa 1976) [epub ahead of print], 2016

21. Jones SB, Jones DB: Surgical aspects and future 
developments of laparoscopy. Anesthesiol Clin North America 19:107-124, 2001

22. Khor WS, Baker B, Amin K, Chan A, Patel K, Wong J: Augmented and virtual reality in surgery-the digital surgical environment: applications, limitations and legal pitfalls. Ann Transl Med 4:454, 2016

23. Kim AH, Kendrick DE, Moorehead PA, Nagavalli A, Miller CP, Liu NT, et al: Endovascular aneurysm repair simulation can lead to decreased fluoroscopy time and accurately delineate the proximal seal zone. J Vasc Surg 64:251-258, 2016

24. Kim HJ, Jung WI, Chang BS, Lee CK, Kang KT, Yeom JS: A prospective, randomized, controlled trial of robot-assisted vs freehand pedicle screw fixation in spine surgery. Int $\mathbf{J}$ Med Robot [epub ahead of print], 2016

25. Konovalov NA, Shevelev IN, Kornienko VN, Nazarenko AG, Zelenkov PV, Isaev KA, et al: [Application of robotic assistance in surgical treatment of degenerative disease of lumbosacral spine.] Vopr Neirokhir 3:10-15, 2010 (Russian)

26. Lanfranco AR, Castellanos AE, Desai JP, Meyers WC: Robotic surgery: a current perspective. Ann Surg 239:14-21, 2004

27. Lee CK, Kim Y, Lee N, Kim B, Kim D, Yi S: Feasibility study of utilization of action camera, GoPro Hero 4, Google Glass and Panasonic HX-A100 in spine surgery. Spine (Phila Pa 1976) [epub ahead of print], 2016

28. Lee JY, Bhowmick DA, Eun DD, Welch WC: Minimally invasive, robot-assisted, anterior lumbar interbody fusion: a technical note. J Neurol Surg A Cent Eur Neurosurg 74:258-261, 2013

29. Lee JY, Lega B, Bhowmick D, Newman JG, O’Malley BW Jr, Weinstein GS, et al: Da Vinci Robot-assisted transoral odontoidectomy for basilar invagination. ORL J Otorhinolaryngol Relat Spec 72:91-95, 2010

30. Lee JY, O’Malley BW, Newman JG, Weinstein GS, Lega B, Diaz J, et al: Transoral robotic surgery of craniocervical junction and atlantoaxial spine: a cadaveric study. J Neurosurg Spine 12:13-18, 2010

31. Lee Z, Lee JY, Welch WC, Eun D: Technique and surgical outcomes of robot-assisted anterior lumbar interbody fusion. J Robot Surg 7:177-185, 2013

32. Lieberman IH, Togawa D, Kayanja MM, Reinhardt MK, Friedlander A, Knoller N, et al: Bone-mounted miniature robotic guidance for pedicle screw and translaminar facet screw placement: Part I-Technical development and a test case result. Neurosurgery 59:641-650, 2006

33. Luciano CJ, Banerjee PP, Sorenson JM, Foley KT, Ansari SA, Rizzi S, et al: Percutaneous spinal fixation simulation with virtual reality and haptics. Neurosurgery 72 (Suppl 1):89-96, 2013

34. Maddahi Y, Zareinia K, Gan LS, Sutherland C, Lama S, Sutherland GR: Treatment of glioma using neuroArm surgical system. BioMed Res Int 2016:9734512, 2016

35. Meier M, Horton K, John H: Da Vinci ${ }^{\odot}$ Skills Simulator ${ }^{\mathrm{TM}}$ : is an early selection of talented console surgeons possible? J Robot Surg 10:289-296, 2016

36. Nagendran M, Gurusamy KS, Aggarwal R, Loizidou M, Davidson BR: Virtual reality training for surgical trainees in laparoscopic surgery. Cochrane Database Syst Rev (8):CD006575, 2013

37. Ni J, Wu L, Fan X, Yang SX: bioinspired intelligent algorithm and its applications for mobile robot control: a survey. Comput Intell Neurosci 2016:3810903, 2016

38. Oechtering J, Kirkpatrick PJ, Ludolph AG, Hans FJ, Sellhaus B, Spiegelberg A, et al: Magnetic microparticles for endovascular aneurysm treatment: in vitro and in vivo experimental results. Neurosurgery 68:1388-1398, 2011

39. Onen MR, Naderi S: Robotic systems in spine surgery. Turk Neurosurg 24:305-311, 2014
40. Pannell JS, Santiago-Dieppa DR, Wali AR, Hirshman BR, Steinberg JA, Cheung VJ, et al: Simulator-based angiography and endovascular neurosurgery curriculum: a longitudinal evaluation of performance following simulator-based angiography training. Cureus 8:e756, 2016

41. Pelargos PE, Nagasawa DT, Lagman C, Tenn S, Demos JV, Lee SJ, et al: Utilizing virtual and augmented reality for educational and clinical enhancements in neurosurgery. J Clin Neurosci 35:1-4, 2017

42. Ponnusamy K, Chewning S, Mohr C: Robotic approaches to the posterior spine. Spine (Phila Pa 1976) 34:2104-2109, 2009

43. Putnam K: Challenges associated with robot-assisted surgery. AORN J 103:7-9, 2016

44. Rasheed N, Amin SH: Developmental and evolutionary lexicon acquisition in cognitive agents/robots with grounding principle: a short review. Comput Intell Neurosci 2016:8571265, 2016

45. Rosa D, Mohr C: Faulty analysis in study of robotic-assisted minimally invasive radical prostatectomy. JAMA Surg 150:371-372, 2015

46. Roser F, Tatagiba M, Maier G: Spinal robotics: current applications and future perspectives. Neurosurgery 72 (Suppl 1):12-18, 2013

47. Saratzis A, Calderbank T, Sidloff D, Bown MJ, Davies RS: Role of simulation in endovascular aneurysm repair (EVAR) training: a preliminary study. Eur J Vasc Endovasc Surg 53:193-198, 2017

48. Satava RM: Surgical robotics: the early chronicles: a personal historical perspective. Surg Laparosc Endosc Percutan Tech 12:6-16, 2002

49. Shademan A, Decker RS, Opfermann JD, Leonard S, Krieger A, Kim PC: Supervised autonomous robotic soft tissue surgery. Sci Transl Med 8:337ra64, 2016

50. Shao HM, Chen JY, Truong TK, Reed IS, Kwoh YS: A new CT-aided robotic stereotaxis system. Proc Annu Symp Comput Appl Med Care 1985:668-672, 1985

51. Sheridan TB: Human-robot interaction: status and challenges. Hum Factors 58:525-532, 2016

52. Spiotta AM, Kellogg RT, Vargas J, Chaudry MI, Turk AS, Turner RD: Diagnostic angiography skill acquisition with a secondary curve catheter: phase 2 of a curriculum-based endovascular simulation program. J Neurointerv Surg 7:777-780, 2015

53. Spiotta AM, Rasmussen PA, Masaryk TJ, Benzel EC, Schlenk R: Simulated diagnostic cerebral angiography in neurosurgical training: a pilot program. J Neurointerv Surg 5:376-381, 2013

54. Stüer C, Ringel F, Stoffel M, Reinke A, Behr M, Meyer B: Robotic technology in spine surgery: current applications and future developments. Acta Neurochir Suppl 109:241-245, 2011

55. Sutherland GR, Wolfsberger S, Lama S, Zarei-nia K: The evolution of neuroArm. Neurosurgery 72 (Suppl 1):27-32, 2013

56. Vadera S, Chan A, Lo T, Gill A, Morenkova A, Phielipp NM, et al: Frameless stereotactic robot-assisted subthalamic nucleus deep brain stimulation: case report. World Neurosurg 97:762.e711-762.e714, 2017

57. Velu JF, Groot Jebbink E, de Vries JP, Slump CH, Geelkerken RH: Validation of the Simbionix PROcedure Rehearsal Studio sizing module: A comparison of software for endovascular aneurysm repair sizing and planning. Vascular 25:80-85, 2017

58. Viirre E, Pryor H, Nagata S, Furness TA III: The virtual retinal display: a new technology for virtual reality and augmented vision in medicine. Stud Health Technol Inform 50:252-257, 1998

59. Walliczek-Dworschak U, Mandapathil M, Fortsch A, 
Teymoortash A, Dworschak P, Werner JA, et al: Structured training on the da Vinci Skills Simulator leads to

improvement in technical performance of robotic novices. Clin Otolaryngol 42:71-80, 2017, 2016

60. Yang MS, Kim KN, Yoon DH, Pennant W, Ha Y: Robotassisted resection of paraspinal Schwannoma. J Korean Med Sci 26:150-153, 2011

61. Yoon JW, Chen RE, Han PK, Si P, Freeman WD, Pirris SM: Technical feasibility and safety of an intraoperative headup display device during spine instrumentation. Int J Med Robot [epub ahead of print], 2016

62. Yudkowsky R, Luciano C, Banerjee P, Schwartz A, Alaraj A, Lemole GM Jr, et al: Practice on an augmented reality/haptic simulator and library of virtual brains improves residents' ability to perform a ventriculostomy. Simul Healthc 8:25-31, 2013

63. Zhao Z, Niu P, Ji X, Sweet RM: State of simulation in healthcare education: an initial survey in Beijing. JSLS 21:e2016.00090, 2017

\section{Disclosures}

Dr. Wang is a consultant for DePuy Spine, K2M, and JoiMax. He holds a patent with DePuy Spine, and he owns stock in ISD.

\section{Author Contributions}

Conception and design: Madhavan, Kolcun, Wang. Acquisition of data: Madhavan, Wang. Analysis and interpretation of data: Madhavan. Drafting the article: Madhavan, Kolcun, Chieng. Critically revising the article: Madhavan, Wang. Reviewed submitted version of manuscript: Chieng. Statistical analysis: Chieng. Administrative/technical/material support: Wang. Study supervision: Wang.

\section{Correspondence}

Karthik Madhavan, Department of Neurological Surgery, University of Miami Miller School of Medicine, Lois Pope Life Center, 1095 NW 14th Terrace (D4-6), Miami, FL 33136. email: drkarthik19@gmail.com. 